\title{
Research on the Color Expression of Public Service Advertisement
}

\author{
Lei Zhang \\ Chongqing College of Electronic Engineering, Chongqing, China
}

Keywords: Color Expression, Public Service Advertisement

\begin{abstract}
In today's era of rapid development of information, advertising as an important form of information dissemination is already an indispensable part of people's daily life, and color as a carrier of this information it plays a pivotal role. To make a public service ad in the ad to stand out to attract the attention of the audience, at the moment left a deep impression, in addition to creative ideas, the color of the visual language whether it is in the physical or psychological, have a considerable impact on it. The color expression of public service advertisement should aim at advertising visual effect, follow the application of advertising color and match principle, adhering to the principle of color application of traditional public service advertisement, and strive to realize the innovation of modern public service advertisement color application.
\end{abstract}

\section{Introduction}

Public service ads are originated in the United States in the 1940s. Public interest advertising in a propaganda, revelation and persuasion of the intention came into being, and gradually in the future into Europe, Asia, and then slowly spread throughout the world, resulting in a growing impact. China in the 20th century, the late 80s, with the market concept of the sprouting and economic development, in 1986 Guiyang TV broadcast for the first time to "save water" as the theme of public service advertising; in October 1987 China Central Television is unique, golden time to open up the "widely advert" column dedicated to play public service ads, this is known as "public service ads" advertising new varieties began to enter the lives of ordinary people. Public service advertising is different from commercial advertising to reflect the social reality to help improve or solve social and public issues as their responsibility.

In the public service advertising design, the expression of color is infinite, in the public service ads in an irreplaceable position and it has a variety of ways of existence, while the potential of a mysterious charm to a certain extent already have emotional and cultural factors, and even aesthetic significance.

The importance of color in the work of public service is very obvious. Color in the "color" and the designer, as if the finishing touch, determine the wonderful work, moving or not. In the public service ads, the color is not isolated, not only to reflect the texture of goods, features, but also to beautify the advertising layout; at the same time with the environment, climate and other aspects to adapt, there are to take into account the different visual change the law, so that advertising more aesthetic. In terms of advertising art, the association caused by color is to attract the audience to participate in, so as to communicate with the audience, so in the process of advertising design to fully consider the audience acceptance and aesthetic is very necessary. It is necessary to put the color and advertising design as a visual element of both research and promotion, precisely the public psychology, let the color of this element. In modern public service advertising reflects its importance. Color on the design itself is the source of life, if there is no color there is no design vitality. Therefore, in accordance with the design needs and color attributes of the correct application, in order to more effectively increase the charm of public service ads and social effects. 


\section{The Role of Color in Public Service Advertising Design}

In the material life and spiritual life of the rapid development of human civilization process, the magic of the charm of magic has been playing an important role, people enjoy the colorful world of colorful wandering, wonderful colors make people have a good vision, you can pin the beautiful ideals and desire. Color beauty has penetrated all aspects of life and the growing development of public service advertising also has a very profound impact. All kinds of advertising have become an indispensable part of people's lives, excellent advertising not only to play a good marketing role, but also to attract people's attention, access to the enjoyment of art. Excellent advertising in addition to winning in the creative, in the form of beauty and color beauty is also doing my part.

First of all, the color of public service advertising design has played a role in the expression of information and emotions. With the rapid development of information, information flow continues to increase, people tend to accept more direct, more simple and clear information, and in fact, simple and direct information is more conducive to the transmission of information. And the color itself is intuitive, so the way through the expression of information more and more attention, the color of the composition is often possible to qualitatively determine the mood of a public service ad, for example, choose blue or red, already decided that the ad is quiet and deep tone or the feeling of passion. In the public service advertising design, often using exciting colors to stimulate the viewer's senses, making the audience's sensory nerve excited, and then to a high degree of attention to advertising and interest, which was impressed. In contrast, the high technological content of the product advertising is often used in the color of silence to reflect the scientific rigor, showing the product has a reliable performance. With the further development of semiotics research, color not only express emotions, but also more directly to the expression of information, such as the principle of sports traffic lights, in the public service ads can be directly used in red forbidden, green on behalf of permission, and so on. The two Coke brand, Pepsi and delicious, respectively, use red and blue as their representative color, appear in the public service ads, the public can quickly reflect the different colors on behalf of the brand.

Second, using color in the public service ads to better improve the picture sense, rich information. In addition to the intuitive features of the color, but also its unique "charm", as mentioned above, we live in the colorful world, the world is color, in general, simple black and white tone of the charm of advertising is far less than the color Strong public service ads, of course, do not rule out creative advertising. Color advertising relative to the general "sketch" ads, the picture is more realistic, more gorgeous color, the image is more vivid, can be more comprehensive expression of advertising information, far from public service ads, color is undoubtedly an important factor to attract the eye. It can be said that color as an external expression of advertising information, is a key factor in the spread of public service advertising. The color does not just refer to the combination of the color of the screen, but also includes the relationship between the shades of light and shade, such as lightness, hue, saturation, etc., but also includes the public interest advertising theme of the emotional expression of color, color makes the picture more saturated, making the text more powerful. In addition, the use of color is often not only a simple arrangement of the combination, but to express the advertising product culture and value is the so-called color symbolic ability.

Finally, as a successful public service ads it must be through the use of color to strengthen the brand and philosophy. Usually the use of color on a brand of good design to form a standardized visual effects, which makes the market more quickly and clearly remember the brand, so the color of the brand image of the establishment of a crucial role. As mentioned above, Pepsi and Coca-Cola is the case. The use of color can enhance the brand awareness, to strengthen the brand of discrimination, of course, through research, analysis, mining, development of these very complex steps on the color positioning, so as to target audience and market, select apply the right color to the creative, to achieve the greatest spread effect. Successful public service ads in the use of color must be successful, this is the public service advertising this visual arts necessary elements. Through a color representation can convey a certain concept, through the positioning of the concept of connotation will be concise condensate, more conducive to the majority of the audience to receive, perception, and finally the 
formation of resonance.

\section{The Color Expression of Public Service Ads}

Use the hue with a sense of shock to attract the audience to watch the interest. From the color in the advertising art began to use the first day, the ad even to find one of the most favorable weapons especially in the charity art. Eyes are a person's soul of the window, and advertising a powerful weapon color, is to seize the audience's eyes "hand" is to let the audience produce "instant memory" killer.

For the purpose of persuasion for the purpose of advertising art, the color is one of the most powerful means of power. The following will be from the example of advertising to analyze the use of shocking colors, to attract the audience to watch interest.

Red, yellow and other warm colors or contrasting strong colors, easy to make people excited, strong visual impact on people, in the first time to attract the attention of consumers to advertising up, so that consumers have a sense of advertising and thus to pay attention to the advertising product information. In the use of advertising color must have a clear and novelty. That is, to have a sense of weight. The vivid color of advertising refers to the color of advertising in the design and use of the process must be from the nature of advertising, advertising is an art of persuasion to achieve the purpose of persuasion first to attract the attention of the advertising audience, and this attention in today's information complex and hectic world, has become increasingly difficult. Even so, the art of advertising is still to use color techniques as much as possible to achieve the audience to produce "instant memory" effect, so the advertising color of the bright and also become more and more important.

Because the color can affect people's feelings, memories, associations and emotions and other physiological and psychological processes, resulting in a specific psychological role, such as cold, heavy, distance, strength and so on, different colors correspond to different psychological reactions. Now public service advertising, the color performance of the unique communication, identification and symbolic role, by a lot of designers and entrepreneurs attach great importance. There are some large foreign companies, large enterprises are carefully selected a color on behalf of their own image color.

With a bright and lively sense of the tone, so that ads produce beautiful and pleasant results. Relatively speaking, solid color, warm color, high brightness and contrast of strong colors can give a fresh and bright, pleasant lively, free and easy sense of beauty. For example, "the protection of water resources posters" using sea blue, reminiscent of the blue sea, produce fresh and cool visual experience, highlighting the ultimate effect of advertising is to make people better living environment "; protection of forest posters" People to the feeling of youth, and give the feeling of glowing youth; "care for children posters," the whole picture quoted golden yellow, giving a rich and colorful education to the children to bring the success of the dream of the visual effects, highlighting its "love children let the children enjoy equal education "propaganda concept. The audience of such advertising information is easy to accept, and the soul of pleasure, the charm of urban villages, excitement and sense of expansion arises spontaneously, easy to contribute to the social welfare of the move, lively colors make people feel happy do not feel the desire to make a contribution to the community, compared to the color of the shock, the extravagance of the impulse to reduce the waste, but the social welfare effect, but a qualitative leap, it will not produce Bought the regret of the phenomenon.

According to the audience's gender, age, customs and other use of advertising color. This principle has two aspects of understanding, one is the audience on the specific color of the fixed impression and association logic; the other is in the national tradition of consideration, each nation because of cultural and other aspects of the color also have their own specific understanding And preferences.

In the plane public service ads, the color of people's minds play an important role is a result of people's life experience, personality, age, sex, occupation, hobbies, customs, religious beliefs and so on a series of factors formed by the people have different psychological feelings also led to different feelings of association. For example, for politicians, red symbolizes the revolution, war, bloodshed; in 
our modern eyes it represents festive and joy. Because of this color on the impact of people, designer in the design is a purpose to choose the color design of people like works. Generally in the advertising design, red is the most vivid and enthusiastic color. This character, in the eyes of the people, the red people to escape the evil, Daixing Daqing symbol; but in the view of the politicians think it is a sign of revolution and victory. While yellow is the highest in color. There are light, transparent, lively, bright and other characteristics. Yellow represents the land, yellow symbolizes power, and it has the color of religion. For orange is the most dazzling in chromatography. Feel warm, gorgeous, excited, warm and so on. There are green eternal topic is also the master of public service advertising. It is the color of nature plants, is the life of strong colors, but also the hope of the season, in the original era and it is this green gave birth to humans. Green in our world symbolizes peace and security. In the plane charity advertisement, the study of the preferences and tendencies in color is to use different schemes for different audiences, and only the color can play its importance in the public announcement.

\section{Conclusion}

With the continuous changes in society, people's lives are constantly improving, the expression of color and appeal is also constantly strengthened, the traditional and non-traditional concept of life will be further integration, public service advertising in the use of color will be further deepened, In the fierce competition in the market to win more attention, we asked us from a deeper point of view to tap the use of color in public service ads. In advertising design, especially in public service advertising color is occupying an extremely important position, it is with the reader's physiological and psychological reactions are closely related. In the ad, the color is better than people's face, in life, people's face can reflect their health and mental state is good. Visible, color in the public service advertising design there is an important value.

\section{References}

[1] Wei Yamin. Contemporary TV public service advertising era[J]. Yalu River (the second half of the month). 2014 (08)

[2] General Administration announced the 2016 annual radio and television public service advertising project evaluation results of 121 works, 61 institutions selected[J]. Radio and television commentary. 2017 (16)

[3] Zhang Hengxi. On Chinese television public service advertising spread [J]. News Communication. 2015 (21)

[4] Yu Jinbao. On the radio and television public service advertising thinking[J]. China Radio and Television Journal. 2016 (05)

[5] Yin Hong. China TV public service advertising a new stage[J]. China Television. 2014 (11)

[6] Xu Shusheng. TV public service advertising editorial style[J]. News Communication. 2014 (02)

[7] Chen Tingting. Chinese TV public service advertising problems and countermeasures[J]. Western Broadcasting and Television. 2014 (08) 